\title{
NIETZSCHE, EL ESTETICISMO Y LAS VANGUARDIAS
}

\author{
Bernal Herrera
}

\begin{abstract}
RESUMEN
En este artículo se analiza la influencia del pensamiento de Nietzsche en la literatura contemporánea y las tendencias estéticas. Se propone que su mayor influencia no surge de explícitas ideas de Nietzsche sobre el arte, sino de sus ideas epistemológicas y ontológicas, las cuales enfatizan en el perspectivismo y estética que permean toda la realidad, y no sólo el terreno de lo estético. Estas características establecen un vínculo entre estética finisecular, movimientos de vanguardia y postmodernidad.
\end{abstract}

\begin{abstract}
The influence of Nietzsche's thought on contemporary literature and aesthetic tendencies is analyzed. The main influence, it is argued, does not arise from Nietzsche's explicit ideas on art, but from his epistemological and ontological ideas, which emphasize the perspectivism and aestheticism that permeate the whole reality, not only the aesthetical realm. These characteristics, it is said, provide a common thread that links fin de siècle aestheticism, avant-garde movements, and postmodernity.
\end{abstract}

En su libro El discurso filosófico de la modernidad, Habermas ve en Nietzsche el pun. to de arranque de la muy discutida posmodernidad, argumentando que con él la crítica de 1: metafísica racionalista occidental se hace, por primera vez, no desde el horizonte de una nue va formulación de la razón sino desde una esfera estética asumida como "lo otro" de la razó El pensamiento nietzscheano constituye, desde esta perspectiva, una otredad que no sólo col lleva una oposición frontal a las categorías racionalistas de interpretación del mundo postul das por la modernidad, sino también la independencia de los parámetros de constitución y ji cio vigentes en la esfera estética. El siguiente paso en el proceso conceptual que llevará al sı gimiento del radical esteticismo finisecular, paso dado por el mismo Nietzsche y retomado $\mathrm{F}$ muchos de sus seguidores posmodernos, es el traslado y la puesta en vigencia de los parán tros estéticos al interior de esferas como la política y la filosófica, tradicionalmente constit das y juzgadas con los parámetros racionalistas de la modernidad. Si el campo de lo estéti representado por su más conspicua manifestación, el arte, venía estando sujeto, al menos d de Platón, a los requerimientos de esferas como las de la política, la religión y la moral, rante el siglo XIX y principios del XX experimenta un proceso de liberación que no sólc 
lleva, al menos en algunas de sus tendencias, a ser concebido como independiente de tales imposiciones externas, sino incluso como modelo para entender otros campos de la realidad. Las manifestaciones literarias de esta no siempre explícita afirmación de la supremacía de los criterios estéticos sobre otros posibles criterios de juicio de la acción y la contemplación, no se hacen esperar a la hoy llamada posmodernidad, sino que remontan cuando menos a las corrientes esteticistas de la literatura de fin de siglo, representadas en Hispanoamérica por el movimiento modernista. Estas corrientes esteticistas, muy esquemáticamente caracterizables por la puesta en primer plano del factor creación implícito en todo texto, en oposición al factor representación priorizado por el polimorfo hilo realista que corre a lo largo de la previa tradición literaria occidental, serán adicionalmente desarrolladas por los movimientos de vanguardia que suceden al modernismo, movimientos de los que buena parte de la literatura contemporánea es directa o indirectamente tributaria.

Ampliamente considerado, el esteticismo presenta una robusta genealogía que atraviesa, con muy diversas manifestaciones y grados de fortaleza, la totalidad de nuestro siglo, para de algún modo rematar en el fenómeno de la posmodernidad, algunos de cuyos rasgos característicos ya habían aflorado, no en pequeña medida por influencia del pensamiento de Nietzsche, en las literaturas de vanguardia. En lo que sigue intentaré caracterizar algunas de las principales contribuciones de Nietzsche al caldo de cultivo en que movimientos tan disímiles como el modernismo, las vanguardias y la posmodernidad encuentran su alimento común.

Empecemos recordando que ya en su primer libro, El nacimiento de la tragedia, Nietzsche enfatiza la importancia de la esfera estética y lamenta su derrota temporal a manos del racionalismo socrático. Desde su título mismo el libro empieza a minar las apolíneas normas de claridad y univocidad propias del racionalismo cuyo triunfo analiza y lamenta. Si pensamos en el Nietzsche filólogo clásico que lo escribe, el título alude al origen de la tragedia en tanto género literario, pero si pensamos en el Nietzsche esteta pregonado por el texto, la tragedia no parece ser otra sino la execrada derrota del arte a manos del racionalismo didáctico que lo pone a su servicio, derrota allí ejemplificada en la trayectoria que lleva del trágico arte de Esquilo al didactismo socrático de Eurípides. La lectura de El nacimiento de la tragedia, por atenta que sea, no nos permite resolver tajantemente la disyuntiva semántica propuesta por el título, forzando al lector a sacrificar uno de los posibles sentidos o a reconocer la imposibilidad de vencer la indeterminación de la escritura nietzscheana, escritura que no se conforma con referirse a los límites de la epistemología racionalista basada en la univocidad del sentido, sino que los pone en escena. La obra de Nietzsche, entonces, se inicia con una reflexión sobre la posición y función del arte, tema que continuará figurando de modo prominente hasta en sus últimos escritos.

Entre las numerosas reflexiones de Nietzsche sobre el arte encontramos no pocas que evidencian su gran perspicacia crítica. Así, cuando en La genealogía de la moral escribe que "Homero no habría creado a Aquiles ni Goethe habría creado a Fausto, si el primero hubiera sido Aquiles, y el segundo, Fausto"1, establece la distancia entre el yo poético y el yo biográfico que, en oposición al ideal romántico todavía vigente en la crítica artística de su época, será característica de buena parte de las concepciones literarias iniciadas en nuestro siglo por el formalismo ruso. Dichas concepciones, resumidas en la afirmación estructuralista de la "muerte del autor", establecen la independencia del texto, más sometido al imperio impersonal del lenguaje que al personal del autor, frente al yo biográfico de su creador, razón última 
del texto según las concepciones románticas. La misma superación del romanticismo se nota en su rechazo de un tono escritural permanentemente expresivo, considerado por él como una falsa intensificación ${ }^{2}$, o en su defensa de las convenciones artísticas: "Todo arte maduro tiene como base un conjunto de convenciones - en tanto es un lenguaje. La convención es la condición del gran arte, no un obstáculo" (Nietzsche 1967: §809)³.

Pero no es en sus reflexiones sobre el arte, sin embargo, donde encontramos sus principales aportes a la estética. Así, la superación de los mencionados aspectos del romanticismo había sido previa o simultáneamente formulada y ejecutada por movimientos como el simbolismo y el parnasianismo. Más aún, las ideas de Nietzsche sobre el arte presentan una bifacialidad que si por un lado lo proyectan hacia el arte contemporáneo, por el otro lo retrotraen hacia posiciones estéticas ya abandonadas por los más modernizantes desarrollos del arte de su época. Si en La voluntad de poder defiende un esteticismo muy cercano al que caracterizará al modernismo y las vanguardias, afirmando: "Se es un artista al precio de considerar todo aquello que los no-artistas llaman 'forma' como contenido, como 'la materia misma'. Se pertenece, entonces, a un mundo al revés, ya que de aquí en adelante el contenido se convierte en algo meramente formal —incluso nuestra vida" (1967: §818), en el mismo texto no sólo hace depender los resultados artísticos de determinadas experiencias vitales —desobedeciendo así su propio llamado a olvidarnos de los artistas y de los orígenes de las obras de arte para concentrarnos en las obras mismas ${ }^{4}$-, sino que postula lo feo como la antítesis del arte: "Lo feo, i.e, la contradicción del arte, lo que es excluido del arte, su No. Cada vez que la declinación, el empobrecimiento de la vida, la impotencia, la desintegración, la degeneración, son sugeridos, aun débilmente, el hombre estético reacciona con su No" (1967: §809). Tal concepción, cuya perfecta puesta en ejecución lo será la exposición de "arte degenerado" organizada por los nazis, lo aleja claramente de amplios sectores del arte contemporáneo, en especial de los más cercanos a los movimientos de vanguardia, que no vacilan en incluir un cierto feísmo entre sus prácticas artísticas. Nietzsche llega a rechazar abiertamente una de las principales características que, según él mismo lo ve, configura el arte contemporáneo: el desdoblamiento del artista en crítico, en teórico del arte. Afirma: "demandar del artista que practique la perspectiva de la audiencia, del crítico, significa demandarle que se empobrezca a sí mismo, a su propio poder creativo (...) Es un honor para el artista si es incapaz de ser un crítico, de otro modo es mitad y mitad, es 'moderno'" (1967: §811). Tal concepción del arte implicaría descartar, en particular, la mayoría de los vanguardismos, dos de cuyas características principales lo son la aspiración a una modernidad entendida como ruptura con el pasado, y la constante teorización sobre el trabajo artístico.

Siendo tan desniveladas las opiniones de Nietzsche sobre el arte, ¿cómo explicar, entonces, su innegablemente fecunda influencia en las concepciones estéticas de nuestro siglo? La respuesta es relativamente simple: los aspectos del pensamiento nietzscheano que han ejercido una fuerte influencia en nuestras concepciones estéticas no son sus ideas explícitas sobre el arte, sino sus ideas sobre el mundo, el lenguaje y el conocimiento, su posición perspectivista y esteticista frente a estos problemas.

Aunque no el primero, Nietzsche es el más radical crítico moderno del lenguaje realista, al que niega las certidumbres epistemológicas y lingüísticas que fundamentaban las concepciones realistas de la literatura. El realismo, no por casualidad el movimiento literario contra el que más apuntan sus baterías tanto el modernismo como las vanguardias, concibe el 
mundo como nítidamente cognoscible, y al conocimiento como una realidad susceptible de ser expresada mediante el lenguaje, visto como medio neutro, transparente, capaz de transmitir verdades objetivas sobre un mundo no menos objetivo. Más que de un valor o de un mundo propio, el lenguaje realista se pretende portador de información sobre realidades no determinadas por el lenguaje, que en lo fundamental se limita a almacenar y transmitir información. Nietzsche, por el contrario, concibe el lenguaje como superficie, una superficie que no oculta en su seno ninguna realidad esencial, ninguna cosa en sí, ninguna verdad objetiva. El lenguaje cesa de ser un medio neutro, transparente, mediante el cual transmitimos verdades objetivas extralingüísticas, para convertirse en instrumento que nos sirve no para transmitir sino para construir el mundo. No por azar la crítica nietzscheana de la metafísica racionalista occidental descansa, en buena medida, en el ataque a lo que él considera la seducción ejercida por el lenguaje propio de dicha tradición, seducción que nos lleva a transformar conceptos creados por la necesidad práctica de ordenar y dominar el mundo, en realidades autónomas dotadas de una existencia independiente de su uso práctico por parte de los usuarios del lenguaje. Afirma Nietzsche: "En el punto donde nuestra ignorancia comienza, más allá del cual no podemos ver más, desplegamos una palabra; por ejemplo la palabra 'yo', la palabra 'hacer', la palabra 'sufrir'. Estas palabras tal vez sean los horizontes de nuestro conocimiento, pero no son verdades" (1967: §482). El lenguaje, entonces, pese a sus aspiraciones a una supuesta objetividad, no es un medio neutro, poseedor de una vectorialidad dirigida a una realidad externa cuya mostración o representación agotaría su función, sino una creación mediante la cual construimos un mundo a la medida de nuestras necesidades e intereses. Lejos de ser ello característica exclusiva de discursos como el de la persuasión partidista o la seducción amorosa, todo lenguaje estaría al servicio de objetivos pragmáticos cuya consecución depende de su capacidad persuasiva. El lenguaje deviene metáfora y la lógica deviene retórica. El mundo mismo, y muy especialmente su esfera cultural, por definición creación del ser humano, se transforma en un texto que no sólo leemos - tal y como pretendían las ciencias naturales según la formulación de Galileo, para quien el mundo es un libro escrito en lenguaje matemático-, sino que también escribimos. De suponer que el mundo es un texto escrito a partir de los gustos, necesidades y preferencias de sus múltiples creadores, a asimilar este proceso de creación al fenómeno de la creación artística, hay sólo un paso que Nietzsche, para quien el arte, siempre al alcance de nuestra mano, vale más que la inexistente verdad objetiva, no vacila en dar: "La fuerza inventiva que creó las categorías trabajó al servicio de nuestras necesidades, o sea de nuestra necesidad de seguridad, para un rápido entendimiento sobre la base de signos y sonidos, por medio de la abreviación. Conceptos como 'substancia', 'sujeto', 'objeto', 'ser' y 'devenir' no tienen nada que ver con verdades metafísicas. Es el poderoso quien convierte los nombres de cosas en normas, y entre los poderosos son los más grandes artistas de la abstracción quienes crearon las categorías" (1967: §513). Esta eliminación de la frontera que solía separar el discurso filosófico del literario mediante la reducción de ambos a pura creación lingüística, reducción teorizada y practicada en Hispanoamérica por Jorge Luis Borges, está en la base del esteticismo propio de la mayoría de los movimientos literarios surgidos a partir de finales del siglo XIX, entre ellos el modernismo y la vanguardia.

Es necesario diferenciar dos etapas en la asimilación y puesta en práctica del esteticismo por parte de las modernas prácticas literarias. En una primera etapa el esteticismo se expresa de dos modos: mediante la postulación de la autonomía de la actividad literaria y 
mediante el reinado del concepto de belleza como parámetro de juicio de la realidad artística. Ambos aspectos están íntimamente relacionados, ya que se aspira a la autonomía de la actividad literaria para escapar a la influencia de una realidad externa concebida como predominantemente antiestética. Este primer momento es el representado en las literaturas francesa e inglesa por el parnasianismo y el decadentismo, y en las de lengua española por el modernismo, todos ellos movimientos que rechazan por igual la exaltada retórica romántica y la descriptiva y analítica del realismo. Independientemente tanto de la coincidencia o no entre sus objetivos y realizaciones, como de la obvia posibilidad de leer sus textos prescindiendo en mayor o menor medida de tales objetivos, el caso es que la retórica romántica pretendía dar cuenta ya de una individualidad concebida como fundadora del fenómeno artístico, ya de los afanes de un pueblo concebido como nación; la retórica realista, por su parte, aspiraba a describir un mundo social considerado fundamentalmente como un problema por resolver. Frente a estas vectorialidades que sitúan la finalidad del lenguaje literario en la expresión de una verdad externa a sí mismo, los movimientos esteticistas finiseculares proclaman la autonomía de la actividad literaria, autonomía ejercida no sólo de cara a la realidad social sino frente al yo biográfico del escritor, convertido de guía oracular en artesano manipulador del lenguaje. Para el esteticismo de fin de siglo la justificación del arte está en el arte mismo, siendo la belleza el único parámetro válido de juicio. Ajeno a toda sujeción a verdades externas y creador de un lenguaje autorreferencial que abandona toda pretensión de transparencia para convertirse en representación de sí mismo, el esteticismo empieza a cumplir la función asignada por Nietzsche al arte: el cuestionamiento y rechazo del culto a la verdad, última encarnación del repudiado ideal ascético. "El arte, en el cual precisamente la mentira se santifica, y la voluntad de engaño tiene a su favor la buena conciencia, se opone al ideal ascético mucho más radicalmente que la ciencia: así lo advirtió el instinto de Platón, el más grande enemigo del arte producido hasta ahora por Europa. Platón contra Homero: éste es el antagonismo total, genuino (...) Una sujeción del artista al servicio del ideal ascético es por ello la más propia corrupción de aquel que pueda haber, y, por desgracia, una de las más frecuentes: pues nada es más corruptible que un artista" (1975: III, 25).

Recordemos que dentro del ideal ascético Nietzsche incluye no sólo su usual sentido religioso, aunque éste también es mantenido, sino en general toda actitud que, tras depreciar los datos de los sentidos y el valor del mundo aparente, postule un supuesto mundo suprasensible más real y duradero, accesible sólo mediante disciplinas y procedimientos que van de la ascesis religiosa a la racionalización científica. En literatura dicho ideal ascético, corruptor del arte, es representado por el realismo y su voluntad de verdad, no siendo casual que en momentos en que la literatura europea acusa la influencia de su variante más cientificista, el naturalismo, Nietzsche estime la corrupción del arte como un fenómeno frecuente. La voluntad de transmitir una verdad externa, alcanzable según el realismo gracias a una transparencia del lenguaje que Nietzsche considera una imposibilidad a-priori, es lo que rechaza el esteticismo literario finisecular, rechazo con el cual empieza a cumplirse el programa nietzscheano para el arte.

Este primer momento del esteticismo moderno todavía aspira, sin embargo, a una cierta trascendencia. Parnasianos, decadentistas y modernistas rechazan la sujeción del arte a la realidad externa, pero todavía creen en un ámbito estético cuya contemplación y expresión es deber del artista. Permea estos movimientos una concepción platónica de la belleza como ideal preexistente a la obra de arte, lo que los lleva a establecer conceptos relativamente rígidos, 
aunque amplios, de belleza. Tal amplitud y rigidez están presentes en el modernismo hispanoamericano, que al tiempo que amplía y renueva los repertorios léxicos, formales y temáticos de la literatura en lengua española en una medida no vista desde el Siglo de Oro español, establece una concepción algo rígida de lo que es bello, y por ende artístico, y lo que no lo es, criterio de exclusión que sus detractores convertirán en la más frecuente acusación dirigida contra el movimiento: su pretendido torremarfilismo.

El esteticismo finisecular, entonces, elimina algunos de los aspectos del platonismo artístico rechazado por Nietzsche, en especial la sujeción del arte a lo real y su función pedagógica, aspectos articulados por Platón en los libros segundo y tercero de La República. Habrá que esperar a la aparición de las vanguardias para que sea abandonado el segundo aspecto del platonismo: el afán de alcanzar mediante el arte algún tipo de trascendencia. Las vanguardias literarias, cuyo nacimiento oficial podemos ubicar arbitrariamente en 1909 con la aparición del Manifiesto futurista de Marinetti, texto traducido y difundido de inmediato en Hispanoamérica por Rubén Darío, se inician con el intento de sustituir el entonces vigente concepto de belleza, el del esteticismo finisecular, por uno nuevo basado en el maquinismo y la velocidad. "Declaramos que el esplendor del mundo se ha enriquecido con una belleza nueva: la belleza de la velocidad. Un automóvil de carrera, con su cofre adornado de gruesos tubos semejantes a serpientes de aliento explosivo... un automóvil rugiente, que parece que corre sobre metrallas, es más bello que la Victoria de Samotracia”, dice famosamente Marinetti en su primer Manifiesto futurista. Rápidamente el dadaísmo radicalizará la propuesta, aboliendo por completo el concepto de belleza y eliminando los últimos residuos de referencialidad dejados en pie por el futurismo. Tal radicalidad no podrá mantenerse por demasiado tiempo, especialmente por la imposibilidad de impedir que la mera negación se transforme en afirmación de nuevas concepciones estéticas, tarea efectuada en Europa por quienes, provenientes del rabiosamente iconoclasta dadaísmo, pasan a fundar el surrealismo, poseedor de una rigurosa ortodoxia que acaba negando el culto a la libertad que dice practicar.

En medio de todos estos cambios y movimientos, que se suceden a una velocidad y con una agresividad en nada inferiores a la del automóvil exaltado por Marinetti, una característica común es discernible: la llegada de las vanguardias hace del lenguaje literario una pura superficie detrás de la cual no se esconden verdades objetivas, bellezas preexistentes ni sentidos fijos. El lenguaje no devela ni la realidad externa ni una esfera estética autónoma pero preexistente, sino que apunta a su propia aparición, constituyendo una realidad textual cuyas relaciones con la externa pueden ser concebidas de muy diverso modo, pero no en términos de reflejo ni de transparente referencialidad. Poseído de una movilidad de sentidos que corresponde al lector ya no tanto determinar sino introducir, el texto no encierra una verdad susceptible de ser rastreada mediante métodos hermenéuticos, sino que desencadena una construcción efectuada por el sujeto en el momento mismo de la lectura, poseedora en adelante de una importancia y de funciones hasta entonces insospechadas. Afirma Nietzsche que no existen hechos sino interpretaciones: "Contra el positivismo, que se detiene en los fenómenos- 'Sólo hay hechos'-, yo diría: No, hechos es precisamente lo que no existe, sólo interpretaciones. No podemos establecer ningún hecho "en sî" " (1967: §481). Esta máxima se encuentra en la raíz de la retórica de la escritura y la lectura postuladas por las vanguardias.

La influencia de Nietzsche sobre las vanguardias, y a través de ellas sobre el grueso de la literatura contemporánea, es múltiple y puede ser diversamente analizada. A nivel teórico, 
sus ideas sobre el carácter constructivo y metafórico del lenguaje, así como su perspectivismo epistemológico, invalidan la noción de objetividad en un doble nivel: el de la referencialidad del lenguaje y el de las concepciones estéticas que rigen la escritura. El rechazo de la objetividad, referencial o estética, constituye una de las principales características de las vanguardias, y se manifiesta de muchas maneras, desde el minado de la autoridad tradicional de la voz narrativa y la exaltación de lo grotesco como modus operandi del arte, hasta la polifonía estructural de los textos, pasando por la primacía de lo onírico y lo subjetivo sobre la descripción objetiva de realidades externas identificables.

Es éste un ámbito en el que las vanguardias hispanoamericanas, en especial en su vertiente narrativa, ejecutan una variación importante respecto de los modelos europeos con base en los cuales suelen ser estudiadas. Interesadas en rechazar de plano el realismo contra el cual se rebelan, las vanguardias europeas crean una escritura que se separa nítidamente tanto de la realidad externa como de su representación tradicional. Ningún lector de textos dadaístas o surrealistas corre el menor peligro de caer en lo que Macedonio Fernández llamó la alucinación realista, la creencia en la continuidad entre la realidad textual y la externa, ya que la distancia que las separa es claramente afirmada y no deja lugar a ninguna duda. Tal es su estrategia, la misma que seguirán en Hispanoamérica lo que podríamos llamar las vanguardias ortodoxas, categoría que agrupa el grueso de la producción de movimientos como el estridentismo mexicano y el ultraísmo argentino, y a autores como Macedonio Fernández. Pero al lado de esta vanguardia ortodoxa existe en la literatura hispanoamericana una serie de obras y autores que yo denominaría la vanguardia heterodoxa, cuyo principal rasgo definitorio es su matizada actitud frente al realismo. En lugar de practicar el rechazo a ultranza de todo elemento realista característico de las vanguardias ortodoxas, las variantes heterodoxas practican una utilización y refuncionalización de algunos elementos realistas. La presencia en los textos heterodoxos de tales elementos los diferencia de las vanguardias europeas, por lo que no suelen ser siquiera considerados como textos de vanguardia. Me refiero a autores como Jorge Luis Borges, Felisberto Hernández y Roberto Arlt, autores que no basan su afiliación vanguardista en la creación de realidades absolutamente excéntricas a los parámetros constitutivos de la realidad externa y cotidiana, rasgo definitorio de las vanguardias ortodoxas, sino en una refuncionalización de elementos realistas que provoca mundos imaginarios ambiguamente fronterizos con el externo. Esta segunda vertiente del vanguardismo, casi unánimemente ignorada por la crítica latinoamericana en virtud de su invisibilidad dentro de los marcos conceptuales europeos que privan en ella, es doblemente significativa dentro de la literatura hispanoamericana por ser aquella con la que muestran más afiliaciones muchos de los escritores contemporáneos más significativos. Casi desaparecidas las experimentaciones formales a ultranza que caracterizan a la vanguardia ortodoxa, autores que van de Juan Rulfo a Julio Cortázar continúan la línea de ambigüedad imaginativa y escritural instaurada por la vanguardia heterodoxa. También a la hora de estudiar las relaciones entre Nietzsche y la literatura, tal vertiente es particularmente importante, por ser la única que, dentro del panorama general de las vanguardias, adopta la técnica que Nietzsche juzgaba más eficaz para atacar el ideal ascético: su distorsionada utilización. Afirma Nietzsche: "El ideal ascético continúa teniendo por el momento una sola especie de verdaderos enemigos y damnificadores: los comediantes de ese ideal, -pues provocan desconfianza" (1975: III, 27). La vanguardia heterodoxa mimetiza, poniéndolos al servicio de muy diversas concepciones literarias, numerosos elementos derivados del 
realismo, y al hacerlo reproduce el gesto de Nietzsche, quien mimetiza el discurso filosófico distorsionándolo y poniéndolo a trabajar al servicio de sus propias concepciones. Nietzsche no se limita a teorizar sobre estos temas, sino que su escritura misma anula esa transparente objetividad que constituye la tradicional pretensión del discurso filosófico. Gracias a su inolvidable estilo, lo hiperbólico de sus afirmaciones y la exhibida arbitrariedad de muchos de sus argumentos, Nietzsche nos recuerda permanentemente que lo que leemos no es la neutra descripción de la realidad, sino un texto construido a partir de muy idiosincrásicas perspectivas y muy subjetivos valores 5 .

La mayoría de las lecturas filosóficas de la obra de Nietzsche intentan hallar un pensamiento coherente, sistemáticamente desarrollado y entendible con base en categorías filosóficas tradicionales, de las cuales la más importante es la de verdad. Tales lecturas intentan dilucidar las verdades transmitidas por Nietzsche, desentrañándolas de la frondosidad de su retórica. Lo cierto es que tal procedimiento ignora el mensaje que más constantemente nos transmite su escritura: la inexistencia de la verdad objetiva y lo ocioso de su búsqueda. Dice Nietzsche: "La voluntad de verdad necesita una crítica — con eso definimos nuestra propia tarea-, el valor de la verdad debe ser puesto en entredicho alguna vez, por vía experimental..." (1975: III, 24). Tal vez toda su obra no sea otra cosa que esta puesta en entredicho.

Ahora bien, aun quienes intentan encontrar sentidos últimos y estables en la obra de Nietzsche, negando con ello uno de los principios básicos del pensamiento nietzscheano, no por ello lo obedecen menos que quienes aceptan el perspectivismo reiteradamente afirmado por él. En efecto, en el momento mismo de distorsionar su pensamiento, tales lecturas no hacen sino obedecer a uno de los principios metodológicos delineados por Nietzsche, para quien toda lectura consiste en un apoderarse de lo escrito, reinterpretándolo y reajustándolo de acuerdo con los intereses y necesidades del lector. Desde esta perspectiva, el auténtico nietzscheanismo de regímenes como el nacional-socialista no fue la vulgarización y utilización de tópicos nietzscheanos como el superhombre y el desprecio por los débiles, sino la voluntad desplegada por los nazis a la hora de distorsionar el pensamiento de Nietzsche en su propio provecho. Dicho de otro modo, Nietzsche es un autor que invita a ser utilizado, a ser puesto al servicio de las nuevas perspectivas que vayan surgiendo. No es por ello azaroso que movimientos tan asociados a la polémica y que prestan tanta atención a los aspectos retóricos y performativos de todo lenguaje como las vanguardias y la posmodernidad, exhiban numerosas afinidades con el pensamiento de Nietzsche. Ya sea, entonces, por influencia directa de sus ideas, ya por haber teorizado y practicado algunos de los más prominentes modos contemporáneos de leer y utilizar los textos con que nos enfrentamos, todo parece indicar que el pensamiento de Nietzsche, para bien y para mal, forma parte importante de nuestro horizonte intelectual. Tal vez el mejor indicador de la amplitud de su gravitación en el pensamiento contemporáneo resida en que es perfectamente factible, hoy en día, ser nietzscheano sin haber leído ninguno de sus textos, ignorando tal vez su nombre mismo.

\section{Notas}

1. Nietzsche, Federico. 1975. La genealogía de la moral. Trad. Andrés Sánchez Pascual. Madrid: Alianza Editorial, III, 4. 
2. 'Falsa 'intensificación' : 1. en el romanticismo: este constante Espressivo no es signo de fuerza, sino de un sentimiento de deficiencia". Nietzsche, Federico. The Will to Power. Ed. Walter Kaufmann. Trans. Walter Kaufmann and R.J. Hollingdale. New York: Vintage, 1967. §826. Citaré parentéticamente de esta edición indicando el número de apartado. Las traducciones son del autor.

3. Para una discusión del romanticismo como iniciador del ataque sistemático a las convenciones véase de Octavio Paz Los hijos del limo. Paz observa, con razón, que el rechazo sistemático de las convenciones inevitablemente se vuelve convencional, y ve en el romanticismo no sólo una ruptura de la tradición, sino el inicio de lo que llama 'la tradición de la ruptura'.

4. "Sin duda lo mejor que puede hacerse es separar hasta tal punto al artista de su obra que no se le tome a aquél con igual seriedad que a ésta. En última instancia él es tan sólo la condición preliminar de su obra, el seno materno, el terreno, a veces el abono y el estiércol sobre el cual y del cual crece aquélla, -y por esto es, en la mayor parte de los casos, algo que se debe olvidar si se quiere gozar de la obra misma. El indagar la procedencia de una obra interesa a los fisiólogos y vivisectores del espíritu: ¡nunca y en ningún caso a los estetas, a los artistas!" (1975: III, 4).

5. Un buen ejemplo de la arbitraria subjetividad desde la que construye muchos de sus argumentos lo proporciona su ataque a los historiadores positivistas: “¡yo no conozco nada que me cause más náusea que una de esas poltronas 'objetivas', que uno de esos perfumados gozadores de la historia, medio cura, medio sátiros, parfum Renan, los cuales delatan ya, con el falsete agudo de su aplauso, qué es lo que les falta, en qué lugar les falta, en qué sitio ha manejado en este caso la Parca su cruel tijera, de un modo, jay!, demasiado quirúrgico!" (1975: III, 26).

\section{Bibliografía}

Habermas, Jürgen. 1990. The Philosophical Discourse of Modernity. Trans. Frederick Lawrence. Cambridge, MA: MIT Press.

Nietzsche, Federico. 1967. The Will to Power. Ed. Walter Kaufmann. Trans. Walter Kaufmann and R.J. Hollingdale. New York: Vintage.

1975. La genealogía de la moral. Trad. Andrés Sánchez Pascual. Madrid: Alianza Editorial.

1981. El origen de la tragedia. Trad. Andrés Sánchez Pascual. Madrid: Alianza Editorial.

Paz, Octavio. 1990. Los hijos del limo. Barcelona: Seix Barral. 